\title{
Expanding Conflicts of Interest in Public Health Research
}

\author{
Vishnu Subrahmanyam*
}

\section{ABSTRACT}

Non-Profit and Non-Governmental Organizations (NPOs/NGOs) often receive research funds from private for-profit corporations through Corporate Social Responsibility (CSR). Harm industries such as tobacco and alcohol have utilized this opportunity to clear themselves of any blame in contributing to the disease burden, thus obscuring the real danger of their products. The association of public health institutions with such harmful industries has given rise to both financial and non-financial Conflicts of Interest (COIs). To resolve conflicts that arise out of this association, institutions have sought prohibition and full disclosure models. This article highlights the necessity to expand conflict of interest and include industries of implicit harm (fast fashion, mining, cosmetics, and sugary drinks) and not limit itself to just tobacco and alcohol. Simultaneously, the article underlines the hurdles in such an expansion. In conclusion, the article provides a hybrid model for conflict assessment that attempts to account for the limitations of a prohibition model as well as a full disclosure model.

Keywords: Harm Industries, Conflict of Interest, Public Health, Corporate Responsibility, Disclosure

\section{INTRODUCTION}

As public health research lacks funding, corporations fill a funding gap by allocating money to nongovernmental organizations and non-profits. ${ }^{1}$ However, the financial involvement of private corporations in public health research raises questions about conflicts of interest and research integrity. ${ }^{2}$ Conflicts of interest must be a consideration in the philosophical framework that public health institutions ought to adopt.

\footnotetext{
* Vishnu Subrahmanyam, Integrated MS Chemistry Pondicherry University, MS Candidate Bioethics KU Leuven
}

(C) 2021 Vishnu Subrahmanyam. This is an open access article distributed under the terms of the Creative Commons Attribution License, which permits unrestricted use, distribution, and reproduction, provided the original author and source are credited. 
The recent focus on promoting a "socially conscious capitalistic environment" has led to the inception of corporate social responsibility ${ }^{3}$ or an obligation of corporations to address social concerns their products or operations might bring about. Corporations engage in responsible actions to improve transparency and be more accountable for their actions. ${ }^{4}$ Some corporations are motivated to be good corporate citizens through ethically profitable practices; they recognize a self-imposed obligation to use their resources to protect, and benefit society and they adhere to a social contract. ${ }^{5}$

Corporate social responsibility has strong parallels with entrepreneurial philanthropy. By investing in research, that benefits the socio-economically disadvantaged, social responsibility initiatives further social goals. ${ }^{6}$ There are two distinct problems with corporate social responsibility models: First, they attempt (but fail) to make up for a poor corporate endeavor like selling cigarettes. Some companies abuse their responsibilities and produce unhealthy goods or engage in practices that are contrary to social good. Furthermore, their philanthropic engagement may be ill-motivated. It enables them to access the sociopolitical domain, benefit from tax breaks, and profit directly from the "generosity" label without changing their core practices. ${ }^{7}$

Second, corporate social responsibility leads to conflicts of interest in public research. Corporations fund public health research as a way to "act" responsible and to further a social goal. ${ }^{8}$ Corporations that fund research at academic institutions, and non-profits pose financial conflicts of interest. ${ }^{9}$

I. Conflict of Interest: Funding Effect and Ethical Engagement

Arguably, tobacco and alcohol industries are in stark contrast to the goals of public health. ${ }^{10}$ Their involvement in and contribution towards public health research may be motivated by a desire to improve their reputation. Harm industries engaging in public health research create a fundamental ethical tension. ${ }^{11}$

Many scholars have defined conflict of interest in a variety of ways. In this article, we take the definition of conflict of interest as "a set of circumstances that creates a risk that professional judgement or actions regarding a primary interest will be unduly influenced by a secondary or a competing interest" 12

Thus, a financial conflict of interest occurs when funding leads to the risk of compromising the research project that is financed by the corporation. "Funding Effect" was coined after a study showed significant differences in research outcomes of private and public-funded drug efficiency safety studies. ${ }^{13}$ Privateindustry-sponsored research produced commercially favorable outcomes in comparison to publicly sponsored studies. ${ }^{14}$ Research sponsored by the tobacco industry had scientists produce biased data, often making the best case for industrial interests. ${ }^{15}$ Receiving funds from for-profit corporations has also led to reduced dissemination of unfavorable results and under-reporting of negative findings. ${ }^{16}$ There is not enough research to assess the value of corporate funding to those in academics. ${ }^{17}$ Qualitative and quantitative empirical research may help shape best practices when engaging with private corporations.

Corporate social responsibility creates an illusion of righteousness. Tobacco companies have funded public health research designed to influence tobacco control policies. ${ }^{18}$ Corporations have used research to further the narrative that personal responsibility plays an outsized role in alcohol consumption, thereby ignoring the social determinants of addiction and programs that include alcohol supply reduction. ${ }^{19} \mathrm{~A}$ similar narrative has pervaded the sugary drinks discussion. ${ }^{20}$

While there are many considerations, there is no homogenous policy to help tackle conflicts of interest in public health research. ${ }^{21}$ Academic journals mandate declaring financial conflicts of interest. ${ }^{22}$ However, declarations should attempt to incorporate an institutional view of values and not restrict themselves to 
personal convictions. Rather than approaching each conflict of interest and using declarations, journals should evaluate conflicts of interest in terms of risk. Such an evaluation also would address embedded research practices that may appear ethical on the surface but represent unrecognized bias. ${ }^{23}$ The Mohammed Ali effect is a good example of this phenomenon. Self-reporting of ethical research behavior by scientists is under representative of actual occurrences of misconduct simply because peers are held to different standards than self. ${ }^{24}$

\section{The Prohibition Model - A Deontological Framework}

The prohibition model discards any research in association with industries that would create a conflict of interest. ${ }^{25}$ Academic institutions or journals that prohibit research by industry limit the ability of harm industries to engage in philanthropic public health research that may reflect pro-industry bias. The nonassociation with harm industries draws from Kant's categorical imperative. In From the Groundwork of the Metaphysics of Morals, Kant ${ }^{26}$ believes that moral behavior exists a priori. If we consider ethics a posteriori, we only deal with what we 'already did,' which is not the basis for a moral system. In a Kantian analysis, non-association with harm industries is the starting point of ethical behavior. Furthermore, in Metaphysics of Morals, Kant ${ }^{27}$ outlines the motivations to act. He posits that ethical actions are motivated by duty and not by self-interest or immediate inclination. Thus, the prohibition model grounds itself in strong ethical imperatives. However, it would limit public health research funding.

\section{The Disclosure Model: Conflicts of Interest are Inevitable}

The disclosure model claims that transparent disclosure procedures are enough to manage conflicts of interest. Often, a placating response to any concern is the disclosure of otherwise unavailable information. ${ }^{28}$ Any disclosure should include enough information about the nature, scope, duration, and monetary forces within the for-profit organizational web to allow institutions to assess the risk to their own reputation of engaging in partnership or publishing research conducted by corporations. ${ }^{29}$ In addition to transparency, disclosure allows for weighing risks and benefits by assessing proportionality. The proportionality principle requires that the benefits of the association or accepting funds from for-profits be great to justify the conflict of interest. ${ }^{30}$ As a result of full disclosure, there is scope for increased accountability from private corporations and public health scholars to ensure that values are upheld throughout the association.

However, disclosure is not always effective as it does not prevent or remedy a conflict of interest. ${ }^{31}$ Disclosure rests on a presumption of wrongdoing and can deter prospective corporate engagement in public health research. However, the risk of deterring research participation is not a concern strong enough to loosen the values a public health institution must strive to achieve. Values such as transparency, proportionality, precautionary measures, and accountability make it easier to navigate disclosure requirements. Disclosure as a standalone method is not a foolproof technique. ${ }^{32}$ Thus, a tailor-made model that can switch between the prohibition model and the disclosure model on a case-by-case basis might be more effective. Furthermore, academics need to ensure reasonable confidence that corporations would disclose financial conflicts of interest as the disclosure requirement often acts on an honor system. In case of non-compliance, either terminating the ties or establishing a legal recourse could be sought as alternatives. 
IV. The Case for Expanding the Definition of Conflicts of Interests

Many industries are explicitly harmful to people. Tobacco and alcohol corporations engage in actions and create products that work against the ideals of public health. Industries like fast fashion, cosmetics, and many others that are seemingly harmless contribute significantly to the deterioration of public health through their treatment of workers, environmental impacts, and lobbying efforts that include relaxing laws meant to protect consumers and workers.

The fashion industry produces large amounts of inexpensive clothing by outsourcing labor to lower- and middle-income countries, ${ }^{33}$ creating environmental and occupational hazards for their citizens. Many countries lack institutional structures to prevent abuse of workers. ${ }^{34}$ Fast fashion also leads to the production of solid waste that ends up in landfills with no efficient mechanism for its disposal. ${ }^{35}$ The cosmetic industry releases a great number of micro-plastics into aquatic systems through face products which lead to a shift in their chemical composition. ${ }^{36}$ The gambling industry harms health as gambling is addictive and can financially harm individuals, families, and interpersonal relationships. ${ }^{37}$ The mining industry has occupational hazards such as inhaling of toxic substances as well as environmental hazards. ${ }^{38}$ The sugary drink industry increases the burden of obesity, diabetes, and cardiovascular disease. ${ }^{39}$

A prohibition model works well with industries that explicitly harm. Thus, non-association with the tobacco and alcohol industry becomes obvious. The difficulty in deciphering conflict of interest through association arises when public health institutions are looking to expand their non-association to industries of implicit harm. When looking to expand non-association into industries such as mining, fast fashion, sugary drinks, etc., we need to move away from a one-size-fits-all approach. Disclosure is not enough as it does not resolve the risk of bias; it merely provides transparency. Yet, a prohibition model would require academic institutions and journals to research funding relationships as well as harmful practices and would lead to less funding for research.

V. The Traffic Light Model: A tailor-made hybrid of prohibition and disclosure

Academic institutions, non-profits, and public health organizations might shape market practices and unearth latent intentions to contradict the social determinants of health if they are able to eliminate bias in public health research.

This section presents a hybrid model for conflict-of-interest assessment and resolution that takes the metaphor of a traffic light. Figure 1 represents a schematic of the hybrid.

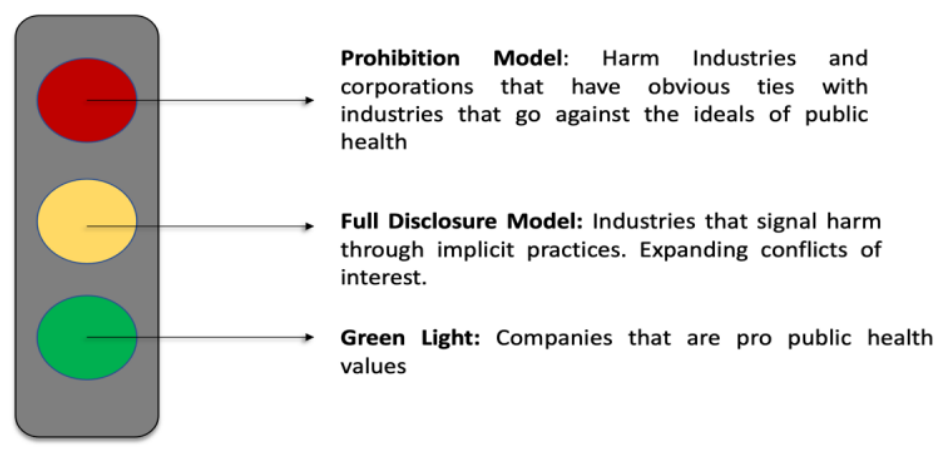

Figure 1: A Schematic of the Traffic Light Hybrid 
As the schematic represents, industries that project values against public health, such as tobacco and alcohol, fall under the red light and hence can be put under non-association, i.e., the prohibition model. Expanding non-association to industries implicit in their harms, such as fast fashion, sugary drinks, mining, companies that exploit labor, would require us to proceed with the disclosure model. As mentioned before, disclosure would require assessing the conflict of interest in terms of proportionality, transparency, accountability, and ensuring that the precautionary principle has been met. Providing a legal recourse at every significant point during research might be helpful to eliminate conflicts that surface during the intermediate stages of research. The entire disclosure model falls under the yellow light urging us to go slow and err on the side of caution.

The green light comprises pro-public health values corporations and exercises impactful operational methods that do not devalue public health goals. However, this should not be taken for face value. Any suspicion of conflict must be dealt with disclosure, and risk-based assessment should precede every funding decision.

The three categories serve as a starting point for public health researchers to invest more in building a framework that helps assess such conflicts. Conflicts of interest are rather dynamic and require constant attention. Examining research practices and funder objectives is crucial. The impact of private corporations on public health research needs to be widely discussed in the academic community. Although the hybrid provides a starting point in designing a more dynamic and flexible framework, the presence of an institutional conflict of interest policy and committee with independent review and oversight of research is also a necessity. ${ }^{40}$

Considering decreased federal funding, scholars have argued the necessity for corporate funding. Besides meeting the financial demand, corporate funding has brought in benefits such as employment opportunities, access to otherwise unavailable tools and technology, and turning academic research into commercially viable practice. ${ }^{41}$ Although the goals of public health research, such as the creation of public goods, affordable and safe housing, access to vaccines, etc., may seem utilitarian, it is important to understand that corporations influence research practices that are more deontological in nature. Research integrity has to do with ethical conduct of research and shaping best practices. Thus, an efficient way to deal with research practice and bias is by invoking the Kantian categorical imperative grounded in procedural ethics rather than consequentialist ethics. A Kantian perspective allows considering conflicts of interest as an institutional value. In addition to focusing on individual research practices, public health institutions need to develop an institutional conflict of interest framework where values of a public health institution shape corporate engagement.

Another closely related discourse that has a significant bearing on corporate involvement is commercial determinants of health. It considers corporations as contributors to disease burden and holds them as part of a structural problem. ${ }^{42}$ By shaping research practices and investing in designing conflicts of interest policies, public health institutions can redefine the narrative of accountability. By actively evaluating financial links within the corporation and assessing risks of bias and influence in research, public health institutions can check the power imbalance that corporations tend to misuse. ${ }^{43}$ More importantly, furthering a narrative that defines disease burden in terms of corporate contribution signals support to those who fight against the injustices perpetrated by large scale corporations. People from lower- and middle-income countries and several indigenous communities have been forced out of their neighborhoods for corporate expansion. ${ }^{44}$ As a public health institution, it is important to support vulnerable groups outpowered and forced into poor living conditions by global corporations. 


\section{CONCLUSION}

The consumption of tobacco, alcohol, polluting motor vehicles, and other products of disease-promoting corporations have presented a significant struggle in improving public health. Engaging with such corporations through corporate social responsibility ventures into highly contentious ethical territory. From a fundamental difference in the values endorsed, for-profit corporations present a conflict of interest in public health research. Public health institutions should be wary of the influence of corporate funding provided through social responsibility programs. Academic bias and the use of corporate social responsibility as a backdoor to legitimizing questionable practices are problematic. The prohibition and disclosure models independently do not perform efficiently against the dynamic nature of conflicts of interest. The hybrid model for institutional conflict-of-interest policy incorporates both the prohibition and disclosure models and allows for switching between them on a case-by-case basis. Managing corporate power requires dealing with conflict of interests broadly and as a risk-susceptibility issue rather than an occurrence issue.

${ }^{1}$ Denier, Y. (2008). Mind the gap! Three Approaches to Scarcity in Health Care. Medicine, Health Care and Philosophy, 11(1), 7387.

${ }^{2}$ Gupta, A., Holla, R., \& Suri, S. (2015). Conflict of Interest in Public Health: Should There be a Law to Prevent It? Indian J Med Ethics, 12(3), 172-7.

${ }^{3}$ de Vries, H. (2016). Invited Commentary: Corporate Social Responsibility and Public Health: An Unwanted Marriage; Resnik, D. B. (2019). Institutional Conflicts of Interest in Academic Research. Science and Engineering Ethics, 25(6), 1661-1669.

${ }^{4}$ Lee, K., \& Bialous, S. A. (2006). Corporate Social Responsibility: Serious Cause for Concern. Tobacco Control, 15(6), 419-419.

${ }^{5}$ Macassa, G., da Cruz Francisco, J., \& McGrath, C. (2017). Corporate social responsibility and population health. Health Science Journal, 11(5), 1-6.

${ }^{6}$ Harvey, C., Gordon, J., \& Maclean, M. (2021). The Ethics of Entrepreneurial Philanthropy. Journal of Business Ethics, 171(1), 3349.

7 Harvey, C., Gordon, J., \& Maclean, M. (2021). The Ethics of Entrepreneurial Philanthropy. Journal of Business Ethics, 171(1), 3349.

8 Resnik, D. B. (2019). Institutional Conflicts of Interest in Academic Research. Science and Engineering Ethics, 25(6), 1661-1669.

${ }^{9}$ Royo Bordonada, M., \& García López, F. (2018). What Is and What Is Not a Conflict of Interest in Public Health Research. European Journal of Public Health, 28(suppl_4), cky213-750.

10 de Vries, H. (2016). Invited Commentary: Corporate Social Responsibility and Public Health: An Unwanted Marriage.

11 Lee, K., \& Bialous, S. A. (2006). Corporate Social Responsibility: Serious Cause for Concern. Tobacco Control, 15(6), 419-419.

12 Gupta, A., Holla, R., \& Suri, S. (2015). Conflict of Interest In Public Health: Should There Be A Law To Prevent It?. Indian J Med Ethics, 12(3), 172-7.

13 Krimsky, S. (2013). Do Financial Conflicts of Interest Bias Research? An Inquiry into The "Funding Effect" Hypothesis. Science, Technology, \& Human Values, 38(4), 566-587.

14 Ibid.

15 Ibid. 
${ }^{16}$ Nakkash, R. T., Mugharbil, S., Alaouié, H., \& Afifi, R. A. (2017). Attitudes of Public Health Academics Toward Receiving Funds from For-Profit Corporations: A Systematic Review. Public Health Ethics, 10(3), 298-303.

17 Nakkash, R. T., Mugharbil, S., Alaouié, H., \& Afifi, R. A. (2017). Attitudes of Public Health Academics Toward Receiving Funds From For-Profit Corporations: A Systematic Review. Public Health Ethics, 10(3), 298-303. (An attempt to review the research failed as there was not data on the "Attitudes of Public Health Academics towards receiving funds from for-profit corporations.")

18 de Vries, H. (2016). Invited Commentary: Corporate Social Responsibility and Public Health: An Unwanted Marriage.

19 Yoon, S., \& Lam, T. H. (2013). The illusion of Righteousness: Corporate Social Responsibility Practices Of The Alcohol Industry. BMC Public Health, 13(1), 1-11.

20 Gupta, A., Holla, R., \& Suri, S. (2015). Conflict of interest in Public Health: Should There Be A Law To Prevent It?. Indian J Med Ethics, 12(3), 172-7.

${ }^{21}$ Shamoo, A. S., \& Resnik, D. B. (2015). Responsible Conduct of Research (3rd ed.). New York: Oxford University Press.

22 Resnik, D. B. (2019). Institutional Conflicts of Interest in Academic Research. Science And Engineering Ethics, 25(6), $1661-1669$.

${ }^{23}$ Field, M. J., \& Lo, B. (Eds.). (2009). Conflict of Interest in Medical Research, Education, And Practice.

24 Fanelli, D. (2009). How Many Scientists Fabricate and Falsify Research? A Systematic Review and Meta-Analysis Of Survey Data. PloS one, 4(5), e5738.

${ }^{25}$ Field, M. J., \& Lo, B. (Eds.). (2009). Conflict of Interest in Medical Research, Education, and Practice.

26 Kant, I. (2008). Groundwork for the Metaphysics of Morals. Yale University Press.

27 Kant, I. (2008). Groundwork for the Metaphysics of Morals. Yale University Press.

${ }^{28}$ Field, M. J., \& Lo, B. (Eds.). (2009). Conflict of Interest In Medical Research, Education, And Practice.

29 Ibld.

30 Childress, James F., R. Gaare Bernheim, R. J. Bonnie, and A. L. Melnick. "Introduction: A Framework For Public Health Ethics." Essentials Of Public Health Ethics 1 (2015): 1-20.

${ }^{31}$ Fleishman, J. L. (1981). The Disclosure Model and Its Limitations. Hastings Center Report, 15-17.

32 Ibid.

33 Bick, R., Halsey, E., \& Ekenga, C. C. (2018). The Global Environmental Injustice of Fast Fashion. Environmental Health, 17(1), 1-4. ${ }^{34}$ Anguelov, N. (2015). The Dirty Side of The Garment Industry: Fast Fashion and Its Negative Impact on Environment and Society. CRC Press.

35 Wicker, A. Fast Fashion Is Creating an Environmental Crisis. Newsweek. September 1, 2016; Available from: https://www.newsweek.com/2016/09/09/old-clothes-fashion-waste-crisis-494824.html. Accessed 13 Aug 2021

${ }^{36}$ Alabi, O. A., Ologbonjaye, K. I., Awosolu, O., \& Alalade, O. E. (2019). Public and Environmental Health Effects of Plastic Wastes Disposal: A Review. J Toxicol Risk Assess, 5(021), 1-13.

${ }^{37}$ Wardle, H., Reith, G., Langham, E., \& Rogers, R. D. (2019). Gambling and Public Health: We Need Policy Action to Prevent Harm. BMJ, 365.

38 Hendryx, M. (2015). The Public Health Impacts of Surface Coal Mining. The Extractive Industries and Society, 2(4), 820-826.

39 Flynn, A., \& Okuonzi, S. A. (2016). Coca-Cola's Multifaceted Threat to Global Public Health. The Lancet, 387(10013), 25. 
40 Resnik, D. B. (2019). Institutional Conflicts of Interest in Academic Research. Science And Engineering Ethics, 25(6), $1661-1669$.

${ }^{41}$ Bayer, R., \& Sampat, B. N. (2016). Corporate Funding for Schools of Public Health: Confronting the Ethical and Economic Challenges. American Journal of Public Health, 106(4), 615-618.

42 McKee, M., \& Stuckler, D. (2018). Revisiting The Corporate and Commercial Determinants of Health. American Journal of Public Health, 108(9), 1167-1170.

${ }^{43}$ Daube, M. (2018). Shining a Light on Industry Research Funding. American Journal of Public Health, 108(11), 1441.

${ }^{44}$ Munarriz, G. (2008). Rhetoric and Reality: The World Bank Development Policies, Mining Corporations, and Indigenous Communities in Latin America. International Community Law Review, 10(4), 431-443. 